\title{
Genetic Analysis of Polymorphisms in Dopamine Receptor and Transporter Genes for Association with Smoking among Cancer Patients
}

\author{
Marat Gordiev $^{\text {a }}$ Paul F. Engstrom ${ }^{b}$ Rustem Khasanov ${ }^{a}$ Anton Moroshek ${ }^{a}$ \\ Rustem Sitdikov ${ }^{a}$ Vladamir Dgavoronkov ${ }^{a}$ Robert A. Schnoll ${ }^{c}$

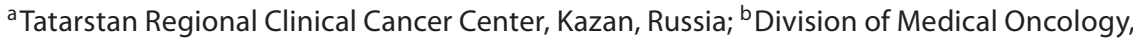 \\ Extramural Research Program, Fox Chase Cancer Center, and ${ }^{C}$ Department of Psychiatry, University of Pennsylvania, \\ Philadelphia, Pa., USA
}

\section{Key Words}

Tobacco $\cdot$ Russia $\cdot$ Cancer patients $\cdot$ Gene $\cdot$ DRD2 $\cdot$ DRD4 $•$

SLC6A3

\begin{abstract}
Background: Smoking among Russian cancer patients may be related to variations in the DRD2/ANKK1 (Taq1), DRD4 (exon III VNTR), and SLC6A3 genes. Methods: Seven hundred fifty patients provided smoking history and DNA. Results: Current smokers were more likely to be DRD2 A2 allele carriers versus nonsmokers (former/never smokers; 69 vs. 56\%; $\mathrm{OR}=1.69 ; 95 \% \mathrm{Cl} 1.13-2.53, \mathrm{p}=0.01)$ and former smokers $(69$ vs. $59 \% ; \mathrm{OR}=1.54 ; 95 \% \mathrm{Cl} 0.97-2.46, \mathrm{p}=0.07)$. Ever smokers (current/former smokers) were more likely to be DRD2 A2 allele carriers versus never smokers ( 65 vs. $55 \%$; $O R=1.50 ; 95 \%$ Cl 1.00-2.27, $\mathrm{p}=0.05$ ). The risk of current smoking among $D R D 2$ A2 allele carriers was present if the DRD4 short allele was also present $(\mathrm{OR}=1.76 ; 95 \% \mathrm{Cl} 1.12-2.78, \mathrm{p}=0.02)$, and the risk of ever smoking among $D R D 2 \mathrm{~A} 2$ allele carriers was present if the $D R D 4$ short allele was also present $(\mathrm{OR}=1.62$; $95 \% \mathrm{Cl} 1.02-2.55, \mathrm{p}=0.04)$. DRD2 A2 allele carriers had a shorter period of previous abstinence versus DRD2 A1 carriers $(p=0.02)$. Effects were not statistically significant when controlling for multiple comparisons. Conclusions: The
\end{abstract}

DRD2 A2 allele may increase the risk of smoking among cancer patients, convergent with studies using non-Western samples. However, additional replication is needed.

Copyright $\odot 2012$ S. Karger AG, Basel

\section{Introduction}

Continued smoking among cancer patients remains an ongoing public health problem, particularly in developing countries such as Russia. Upwards of about one third of Russian cancer patients continue to smoke following diagnosis, and the intention to quit is relatively low $[1,2]$. Given the risks of continued smoking in this population, including diminished treatment efficacy, increased risk of death, and worsening of the quality of life [3], identifying correlates of smoking among cancer patients to guide treatment implementation is a priority.

Research on the neurobiology of nicotine dependence underscores the role of dopamine [4]. Nicotine binds to and stimulates nicotinic acetylcholine receptors (nAChRs) [5, 6], increasing dopamine levels [7, 8]. As with other drugs of abuse, this dopamine increase is experienced as rewarding and perpetuates drug dependence [9]. Polymorphisms in genes that modulate the effects of nic-

\section{KARGER}

Fax +4161306 1234

E-Mail karger@karger.ch

www.karger.com
(ㄷ) 2012 S. Karger AG, Basel

$1022-6877 / 13 / 0192-0105 \$ 38.00 / 0$

Accessible online at:

www.karger.com/ear
Robert A. Schnoll, $\mathrm{PhD}$

Department of Psychiatry, University of Pennsylvania

3535 Market Street, 4th Floor

Philadelphia, PA 19104 (USA)

E-Mail schnoll@mail.med.upenn.edu 
Table 1. Descriptive sample data $(n=750)$

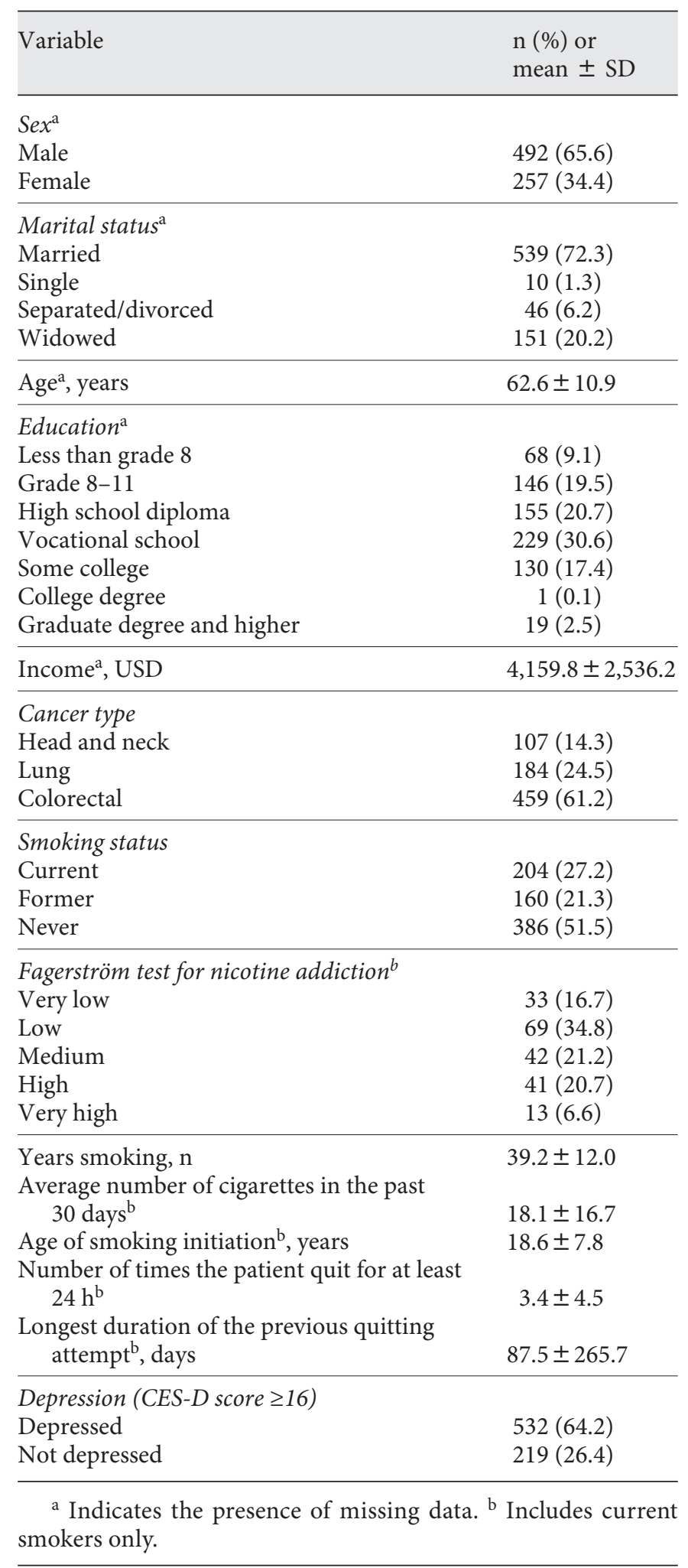

otine on $\mathrm{nAChRs,} \mathrm{therefore,} \mathrm{have} \mathrm{been} \mathrm{examined} \mathrm{as} \mathrm{risk}$ factors for nicotine dependence [10] and biomarkers of treatment response [11].

Variants of dopaminergic genes have been evaluated as correlates of smoking behavior. The Taq1A polymorphism situated on the ANKK1 gene, located $10 \mathrm{~kb}$ downstream in the 3'-flanking region of the dopamine receptor 2 gene (DRD2), decreases D2 receptor binding [12]. Initial studies linked the A1 allele to a greater risk of smoking [13], nicotine dependence [14], and progression from experimenting with tobacco to regular use [15]; however, this relationship has not been consistently replicated [16]. The dopamine transporter gene SLC6A3, which transports extracellular dopamine out of the synapse, has a 40-bp functional repeat polymorphism, and the 9-repeat allele lowers transporter expression [17]. The SLC6A3 9-repeat polymorphism has been related to longer quitting durations and a greater likelihood of cessation [18-20], although not in all studies [21]. Lastly, the functionality of $D R D 4$ exon III variable number tandem repeat (VNTR) polymorphisms has been identified, with the 'long' alleles ( $\geq 7$ repeats) related to a blunted intracellular response to dopamine in vitro versus 'short' alleles ( $\leq 6$ repeats) [22]. Individuals with long alleles are less likely to quit smoking $[23,24]$ and report higher rates of smoking and a younger age of smoking initiation [14, 25]. However, this relationship was not replicated in a recent study [26].

To date, no study has examined these variants in association with smoking among cancer patients. Such a study should be large and include a sample with low ethnic admixture [27, 28]. The present study evaluated the relationship between variants in genes functionally associated with dopamine availability with smoking in a large sample of Russian cancer patients. Results from this study may help guide treatments for a subgroup of smokers who are understudied and at particular risk for adverse health consequences from smoking.

\section{Methods}

\section{Patients}

The study sample was comprised of 750 patients diagnosed with cancer within 30 days of study enrollment and receiving care at Tatarstan Regional Clinical Cancer Center (TRCC) in Kazan, Russia (table 1). Participants were diagnosed with head and neck, colorectal, or lung cancer and were over age 18. These tumor sites were selected since they have a high frequency of smoking [1]. Eighty-nine patients refused to enroll or provided incomplete data (participation rate $=89 \%$ ). 


\section{Procedures}

All procedures were approved by the ethics committee of the TRCC. A designated research assistant used daily physician schedules to identify patients and determine eligibility and willingness to enroll into the study. Informed consent was ascertained. The research assistant conducted an assessment in a private clinic area, which included surveys and the collection of a blood sample for genetic analysis. Participants were given USD 3.00 for completing the assessment. Smokers were given a smoking cessation treatment manual [29].

\section{Measures}

Demographic and Medical Data

Demographic information (e.g. gender, age) and medical data (e.g. tumor site) were collected.

\section{Depression}

The Center for Epidemiologic Studies depression scale (CESD) is a 20-item Likert measure used to assess depressive symptoms [30]. The CES-D was administered to control for variation in smoking behavior attributable to depression symptoms [2].

\section{Genotyping}

Blood samples were collected on FTA bloodspot cards and analyzed at the TRCC using polymerase chain reaction (PCR) methods. Genotyping of the DRD2 TaqIA was performed using a fluorogenic 5'-nuclease assay as described in the NCI SNP500 Cancer Database (http://variantgps.nci.nih.gov/cgfseq/pages/home.do). A 25-ul TaqMan reaction was setup in a 96-well plate using $20 \mathrm{ng}$ of genomic DNA, $2 \times$ TaqMan Universal PCR MasterMix, $900 \mathrm{nM}$ primers (forward: 5'-GTGTGCAGCTCACTCCATCCT, reverse: 5'-GCAACACAGCCATCCTCAAA), and $200 \mathrm{~nm}$ TaqMan-MGB probes $($ T probe $=$ FAM 5' - TGCCTTGACCAGCAC, $\mathrm{C}$ probe $=$ VIC 5'-TGCCTCGACCAGCA). Patients were identified as A1 (A1/A1 or A1/A2) or A2 (A2/A2) allele carriers. Genotyping of SLC6A3 was performed according to past studies [31]. Genomic DNA was amplified for 35 cycles; each cycle consisted of denaturation for $1 \mathrm{~min}$ at $93^{\circ} \mathrm{C}$ and annealing/elongation for $1 \mathrm{~min}$ at $72^{\circ} \mathrm{C}$. The following oligonucleotide primers were used: $5^{\prime}$ TGTGGTGTAGGGAACGGCCTGAG-3' and 5'-CTTCCTGGAGGTCACGGCTCAAGG-3'. PCR products were electrophoretically separated on a $5 \%$ polyacrylamide gel and their molecular weights calculated by comparing their rate of migration with that of known molecular weight standards. The number of copies of the 40-base pair repeat present was determined from the size of the product. Participants were categorized as having the 9-repeat allele (i.e. $9 / 9$ or $9 /{ }^{*}$ vs. ${ }^{*} /{ }^{*}$, where ${ }^{*}$ is alleles other than 9 ). Lastly, the 48 -bp variable nucleotide tandem repeat of DRD4 was assessed following procedures used previously [24]. The polymorphic region within exon 3 was amplified by PCR and fragments ranging from 270 to $570 \mathrm{bp}$, containing 2-8 repeats, were resolved by electrophoresis on a $3 \%$ agarose gel and detected with ethidium bromide staining. Patients were coded as short ( $\leq 6$ repeats) or long ( $\geq 7$ repeats) allele carriers.

\section{Smoking Behaviors}

Our primary outcome was smoking status based on self-report and defined as current (i.e. smokes regularly, cut down, or once in a while), former (i.e. used to smoke but no longer does), or never (i.e. never smoked even a puff of one cigarette) smoker as done previously [1] and recommended with cancer patients [32]. As secondary outcomes, assessed only among current smokers, we examined the age of initiation, years smoked, number of previous 24-hour quitting attempts, longest duration of the previous quitting attempt, current smoking rate, and level of nicotine dependence measured by the Fagerström test for nicotine dependence (FTND) [33].

\section{Statistical Analyses}

Descriptive statistics were computed to delineate the characteristics of the present sample. The $\chi^{2}$ likelihood ratio test was used to assess Hardy-Weinberg equilibrium. Separate multiple logistic regression models were examined for each gene and gene $\times$ gene interaction predicting smoking status. Following the methods of Das et al. [26], models compared current smokers to former smokers, current smokers to nonsmokers (former and never smokers combined), and ever smokers (current and former smokers combined) to never smokers. Models controlled for gender, tumor type, and depression since these variables have been associated previously with smoking behavior among cancer patients $[1,2]$. OR and $95 \%$ CI were computed for predictors. By convention, the probability value of 0.05 or less was considered statistically significant but, to be more conservative, a Bonferroni correction was applied for multiple comparisons as well. As done in a previous study [34], the correction was applied to each set of comparisons for the primary outcome (e.g. current vs. former smokers for the 3 main effects of each gene and the three interaction effects) and the secondary outcome (e.g. 6 dependent variables across DRD2). Thus, for each comparison, the adjusted $\mathrm{p}$ value for significance testing was 0.009 . Analysis of variance was used to assess differences between genetic alleles in terms of the age of smoking initiation, years smoked, number of previous 24hour quitting attempts, longest duration of the previous quitting attempt, current smoking rate, and level of nicotine dependence. Power estimates calculated during the planning of this study assumed effect sizes for genetic associations based on previous studies in the general population $[19,24,27]$. Analyses were conducted using the Statistical Package for the Social Sciences (version 20).

\section{Results}

\section{Genetic Associations with Smoking Status}

The frequencies of alleles for each gene are shown in table 2 . The present frequencies did not differ from the expected frequencies based on the Hardy-Weinberg test of equilibrium (for DRD2, $\chi^{2}[1]=1.95, \mathrm{p}=0.16$; for $D R D 4$, $\chi^{2}[1]=1.75, \mathrm{p}=0.19$, and for SLC6A3, $\chi^{2}[1]=1.41, \mathrm{p}=$ $0.23)$. The $D R D 2$ genotype was related to smoking status in two models based on the conventional p value cut-off. Current smokers were more likely to be DRD2 A2 allele carriers (A2/A2) versus nonsmokers (former and never smokers; 69 vs. $56 \%$; OR $=1.69 ; 95 \%$ CI 1.13-2.53, $\mathrm{p}=$ 0.01). Ever smokers (current and former smokers) were more likely to be DRD2 A2 allele carriers (A2/A2) versus never smokers (65 vs. 55\%; OR $=1.50 ; 95 \%$ CI 1.00-2.27, 
Table 2. Frequencies of genetic alleles by smoking status

\begin{tabular}{|c|c|c|c|c|c|}
\hline Gene & $\begin{array}{l}\text { Current } \\
\text { smokers, n (\%) }\end{array}$ & $\begin{array}{l}\text { Former } \\
\text { smokers, n (\%) }\end{array}$ & $\begin{array}{l}\text { Never } \\
\text { smokers, n (\%) }\end{array}$ & $\begin{array}{l}\text { Nonsmokers }{ }^{\mathrm{a}} \text {, } \\
\mathrm{n}(\%)\end{array}$ & $\begin{array}{l}\text { Ever } \\
\text { Smokers }{ }^{\mathrm{b}}, \mathrm{n}(\%)\end{array}$ \\
\hline \multicolumn{6}{|l|}{ DRD2 } \\
\hline $\mathrm{A} 1 / \mathrm{A} 1$ or $\mathrm{A} 1 / \mathrm{A} 2$ & $62(31)$ & $65(41)$ & $172(45)$ & $237(44)$ & $127(35)$ \\
\hline $\mathrm{A} 2 / \mathrm{A} 2$ & $140(69)^{c, e}$ & $92(59)^{c}$ & $209(55)^{\mathrm{d}}$ & $301(56)^{e}$ & $232(65)^{\mathrm{d}}$ \\
\hline \multicolumn{6}{|l|}{ DRD4 } \\
\hline Short ( $\leq 6$ repeats) & $146(73)$ & $108(70)$ & $279(73)$ & $387(73)$ & $254(72)$ \\
\hline Long ( $\geq 7$ repeats) & $55(27)$ & $46(30)$ & $101(27)$ & $147(27)$ & $101(29)$ \\
\hline \multicolumn{6}{|l|}{ SLC6A3 } \\
\hline 9-repeat allele & $62(30)$ & $52(33)$ & $96(25)$ & 148 (27) & $114(31)$ \\
\hline 10-repeat allele & $142(70)$ & $108(67)$ & $290(75)$ & $398(73)$ & $250(69)$ \\
\hline
\end{tabular}

${ }^{a}$ Former and never combined. ${ }^{b}$ Current and former combined. ${ }^{c}$ Comparison with matching superscript indicates $\mathrm{p}=0.07 .{ }^{\mathrm{d}}$ Comparison with matching superscript indicates $\mathrm{p}=0.05 .{ }^{\mathrm{e}}$ Comparison with matching superscript indicates $\mathrm{p}=0.01$.

$\mathrm{p}=0.05)$. In addition, current smokers were more likely to be $D R D 2$ A2 allele carriers (A2/A2) versus former smokers, although this comparison represented only a trend based on convention ( 69 vs. $59 \%$; OR $=1.54$; $95 \%$ CI 0.97-2.46, $\mathrm{p}=0.07$ ). Models for DRD4 and SLC6A3 yielded no significant relationships between genotypes and smoking status. Furthermore, no model reached statistical significance based on the Bonferroni correction for multiple testing.

Two models that tested gene-gene interactions yielded significant relationships with smoking status based on the conventional $p$ value cut-off. Participants were more likely to be current smokers versus nonsmokers (former and never) if they possessed the DRD2 A2 allele (A2/A2) and the short allele for DRD4 (72 vs. $55 \%$ ), but not the DRD4 long allele (62 vs. $58 \%$; OR $=1.76,95 \%$ CI 1.12 $2.78, \mathrm{p}=0.02$ ). In addition, participants were more likely to be ever smokers (current and former) versus never smokers if they possessed the DRD2 A2 allele (A2/A2) and the short allele for DRD4 (67 vs. $54 \%$ ), but not the DRD4 long allele (60 vs. $57 \%$; OR $=1.62$; $95 \%$ CI $1.02-$ $2.55, \mathrm{p}=0.04)$. Further, no model reached statistical significance based on the Bonferroni correction for multiple testing.

\section{Genetic Associations with Smoking Characteristics among Current Smokers}

No associations were found between $D R D 2, D R D 4$, and SLC6A3 alleles and age of initiation, years smoked, number of previous 24-hour quitting attempts, current smoking rate, and level of nicotine dependence. Partici- pants who were $D R D 2$ A2 allele carriers reported a significantly shorter previous quitting attempt $(M=56.8$ days; $\mathrm{SD}=160.1)$ versus carriers of the $D R D 2$ A1 allele $[\mathrm{M}=152.9$ days; $\mathrm{SD}=411.7 ; \mathrm{F}(1,190)=5.44, \mathrm{p}=0.02]$, although this was not statistically significant based on the Bonferroni correction.

\section{Discussion}

The results of the present study suggest that the risk of smoking may be associated with the A2 allele of DRD2. Using the conventional p value cut-off, the A2 allele was related to a greater likelihood of continued tobacco use following diagnosis as well as ever having been a smoker. In addition, $D R D 2 \mathrm{~A} 2$ allele carriers reported a shorter average duration of past smoking cessation. As such, this patient subgroup may require targeted smoking cessation interventions, particularly if the short allele for DRD4 is also present. However, when correcting for multiple comparisons, these relationships were no longer considered statistically significant. Such a correction may also increase the probability of a type II error. Thus, we discuss the present findings in relation to past studies, yet with caution given the results when considering the correction for multiple testing.

The present results are divergent from studies that have identified the A1 allele for DRD2 as a correlate of smoking $[13,35]$. However, studies using non-Western samples have found that the A2 allele for DRD2 was associated with smoking. Two studies reported that the DRD2 A2 al- 
lele was associated with a greater risk of tobacco use in Japanese samples [36, 37], as did a study with a Polish sample [34]. Taken together, these results are suggestive of the possibility that ethnic differences may influence the relationship between DRD2 alleles and smoking. It is possible that other functional genetic variants, which differ across these ethnic groups, influence the relationship between DRD2 alleles and smoking. Alternatively, cultural differences that covary with geographic and ethnic factors could moderate the relationship between DRD2 alleles and smoking and explain these divergent findings across samples. It is also worth noting that a recent meta-analysis showed that the effects of $D R D 2$ genetic alleles vary across different smoking phenotypes (e.g. smoking persistence vs. smoking rate) and depend on the proportion of men in a particular sample [38]. The gender effect noted in this meta-analysis is particularly relevant given that the present sample was comprised of $65 \%$ males. Further, since the DRD2 A1 allele is in linkage disequilibrium (LD) with other DRD2 variants and possibly other variants of the $A N K K 1$ gene, it is plausible that other functional variants in $D R D 2$ influence smoking phenotypes. While it is unclear if the LD patterns for DRD2 are different across the geographic regions, a previous study found variation in the relationship between $D R D 2$ variants and Parkinson's disease across racial/ethnic groups that may be attributable to differences in LD [39].

The interaction with $D R D 4$, suggesting a greater risk of smoking among the short allele carriers, is inconsistent with previous studies as well $[14,23,36]$. However, among depressed smokers, carriers of the DRD4 short allele are more likely to smoke to alleviate depression symptoms, an effect not detected among DRD4 long allele carriers [40]. The high rate of depression in the present sample ( $64 \%$, based on a cut-off of $\geq 16$ on the CES-D) may explain the present finding, indicating that the relationship between $D R D 4$ alleles and smoking, in part, depends on the presence of depression symptoms [40].

The present results also suggest that variants of $D R D 4$ and SLC6A3 may have little association with smoking phenotypes. While null findings concerning smoking phenotypes and these genes have been reported [21,26], it may also be the case that differences across studies in the definitions of smoking phenotypes explain contradictory findings. There was some indication in the present analyses that $D R D 4$ variants interact with $D R D 2$ variants to predict smoking phenotypes, so other gene $\times$ gene interactions not tested here may be important for other smoking phenotypes for DRD4 and for SLC6A3 variants.

Genes and Smoking among Cancer Patients
Study limitations should be considered. First, although the present sample was relatively large, it may still have been inadequate to provide sufficient statistical power to consider gene $\times$ gene interactions. Second, when considering the results in terms of the correction for multiple testing, there were no comparisons that reached statistical significance. As such, replication is critical to verify that the possible relationships noted in the present study were not found simply by chance. Third, while the rate of misreporting of smoking status is low in this population and unrelated to prediction models [1], the lack of bioverification of self-reported smoking may have affected study results. Fourth, the present study focused on only a certain subset of candidate genes and very recent data suggests a possible role of variants of genes not tested here such as variation in the neuropeptide $\mathrm{Y}$ gene promoter [41]. Fifth, the candidate gene approach assumes a narrow conceptual framework for understanding nicotine dependence. Recent methods in genetic analysis, including genome-wide and deep sequencing analysis, offer more powerful approaches to identifying genetic contributions to disease risk. Finally, the prevalence of never smoking in the present study (52\%) was higher than that found in previous studies (37-43\%) [1,2], which may have affected the present results.

Nevertheless, the present findings contribute to the growing literature suggesting that the relationship between $D R D 2$ genetic variants and smoking may differ across Western and non-Western samples. Further, the present findings offer some support for the identification of DRD2 A2 allele carriers and targeted treatment with smoking cessation treatments including bupropion. Previous studies have suggested that carriers of the DRD2 A2 allele are more likely to respond to bupropion compared to A1 allele carriers [42]. Given the high rate of tobacco use following diagnosis identified in these patients in the present study and in past studies $[1,2]$, the need for empirical methods for targeted treatments for nicotine dependence is critical and hopefully will yield improved clinical outcomes for this understudied population.

\section{Acknowledgments}

This study was funded by grant R03 TW007164 from the National Cancer Institute. The authors thank the American-Russian Cancer Alliance and Ms. Sophia Michaelson and Mr. Alan Howald for their assistance with coordinating this study. The authors thank Dr. Paul Wileyto as well for assistance with this paper. 


\section{References}

$\checkmark 1$ Schnoll RA, Engstrom PF, Subramanian S, Demidov L, Wielt D, Tighiouart M: Prevalence and correlates of tobacco use among Russian cancer patients: implications for the development of smoking cessation interventions at a cancer center in Russia. Int J Behav Med 2006;13:16-25.

-2 Schnoll RA, Subramanian S, Engstrom PF, Martinez E: Correlates of continued tobacco use and intention to quit smoking among Russian cancer patients. Int J Behav Med 2011;18:325-332.

>3 Klosky JL, Tyc VL, Garces-Webb DM, Buscemi J, Klesges RC, Hudson MM: Emerging issues in smoking among adolescent and adult cancer survivors: a comprehensive review. Cancer 2007;110:2408-2419.

$\checkmark 4$ Markou A: Neurobiology of nicotine dependence. Philos Trans R Soc Lond B Biol Sci 2008;363:3159-3168.

5 Mifsud JC, Hernandez, L, Hoebel, BG: Nicotine infused into the nucleus accumbens increases synaptic dopamine as measured by in vivo microdialysis. Brain Res 1989;478:365367.

6 Pidoplichko VI, DeBiasi M, Williams JT, Dani JA: Nicotine activates and desensitizes midbrain dopamine neurons. Nature 1997; 390:401-404.

7 Rice ME, Cragg SJ: Nicotine amplifies reward-related dopamine signals in striatum. Nat Neurosci 2004;7:583-584.

$\checkmark 8$ Rao TS, Correa, LD, Adams, P, Santori, EM, Sacaan, AI: Pharmacological characterization of dopamine, norepinephrine and serotonin release in the rat prefrontal cortex by neuronal nicotinic acetylcholine receptor agonists. Brain Res 2003;990:203-208.

$\checkmark 9$ Nestler EJ: Is there a common molecular pathway for addiction? Nat Neurosci 2005;8: 1445-1449.

10 Ray R, Schnoll RA, Lerman C: Nicotine dependence and pharmacogenetics; in Steptoe A (ed): Handbook of Behavioral Medicine. New York, Springer, 2010, pp 479-498.

11 Schnoll RA, Leone F: Biomarkers to optimize the treatment of nicotine dependence. Biomark Med 2011;5:745-761.

-12 Thompson J, Thomas N, Singleton A, Piggott M, Lloyd S, Perry EK, Morris CM, Perry RH, Ferrier IN, Court JA: D2 dopamine receptor gene (DRD2) Taq1 A polymorphism: reduced dopamine $\mathrm{D} 2$ receptor binding in the human striatum associated with the A1 allele. Pharmacogenetics 1997;7:479-484.

-13 Comings DE, Ferry L, Bradshaw-Robinson S, Burchette R, Chiu C, Muhleman D: The dopamine D2 receptor (DRD2) gene: a genetic risk factor in smoking. Pharmacogenetics 1996;6:73-79.
14 Laucht M, Becker K, Frank J, Schmidt MH, Esser G, Treutlein J, Skowronek MH, Schumann G: Genetic variation in dopamine pathways differentially associated with smoking progression in adolescence. J Am Acad Child Adolesc Psychiatry 2008;47:673-681.

15 Audrain-McGovern J, Lerman C, Wileyto EP, Rodriguez D, Shields PG: Interacting effects of genetic predisposition and depression on adolescent smoking progression. Am J Psychiatry 2004;161:1224-1230.

16 Munafò M, Johnstone EC, Murphy MF, Aveyard P: Lack of association of DRD2 rs1800497 (Taq1A) polymorphism with smoking cessation in a nicotine replacement therapy randomized trial. Nicotine Tob Res 2009;11:404-407.

17 Heinz A, Goldman D, Jones DW, Palmour R, Hommer D, Gorey JG, Lee KS, Linnoila M, Weinberger DR: Genotype influences in vivo dopamine transporter availability in human striatum. Neuropsychopharmacology 2000;22:133-139.

18 Lerman C, Caporaso NE, Audrain J, Main D Bowman ED, Lockshin B, Boyd NR, Shields PG: Evidence suggesting the role of specific genetic factors in cigarette smoking. Health Psychol 1999; 18:14-20.

-19 Sabol SZ, Nelson ML, Fisher C, Gunzerath L, Brody CL, Hu S, Sirota LA, Marcus SE, Greenberg BD, Lucas FR 4th, Benjamin J, Murphy DL, Hamer DH: A genetic association for cigarette smoking behavior. Health Psychol 1999;18:7-13.

20 Timberlake DS, Haberstick BC, Lessem JM, Smolen A, Ehringer M, Hewitt JK, Hopfer C: An association between the DAT1 polymorphism and smoking behavior in young adults from the National Longitudinal Study of Adolescent Health. Health Psychol 2006;25: 190-197.

21 Jorm AF, Henderson AS, Jacomb PA, Christensen H, Korten AE, Rodgers B, Tan X, Easteal S: Association of smoking and personality with a polymorphism of the dopamine transporter gene: results from a community survey. Am J Med Genet 2000;12:331-334.

-22 Asghari V, Sanyal S, Buchwaldt S, Paterson A, Jovanovic V, Van Tol HH: Modulation of intracellular cyclic AMP levels by different human dopamine D4 receptor variants. J Neurochem 1995;65:1157-1165.

23 David SP, Munafò MR, Murphy MF, Proctor M, Walton RT, Johnstone EC: Genetic variation in the dopamine D4 receptor (DRD4) gene and smoking cessation: follow-up of a randomised clinical trial of transdermal nicotine patch. Pharmacogenomics J 2008;8: 122-128.

-24 Shields PG, Lerman C, Audrain J, Bowman ED, Main D, Boyd NR, Caporaso NE: Dopamine D4 receptors and the risk of cigarette smoking in African-Americans and Caucasians. Cancer Epidemiol Biomarkers Prev 1998;7:453-458.
25 David SP, Munafò MR: Genetic variation in the dopamine pathway and smoking cessation. Pharmacogenomics 2008;9:1307-1321.

26 Das D, Tan X, Easteal S: Effect of model choice in genetic association studies: DRD4 exon III VNTR and cigarette use in young adults. Am J Med Genet B Neuropsychiatr Genet 2011;156B:346-351.

27 Singleton AB, Thomson JH, Morris CM, Court JA, Lloyd S, Cholerton S: Lack of association between the dopamine $\mathrm{D} 2$ receptor gene allele DRD2*A1 and cigarette smoking in a United Kingdom population. Pharmacogenetics 1998;8:125-128.

28 Wacholder S, Rothman N, Caporaso N: Population stratification in epidemiologic studies of common genetic variants and cancer: quantification of bias. J Natl Cancer Inst 2000;92:1151-1158.

29 USDHHS: Smoking: Facts and Tips for Quitting. Bethesda, National Institutes of Health, 1993.

$>30$ Radloff LS: The CES-D: a self-report depression scale for research in the general population. Appl Psychol Meas 1977;1:385-401.

-31 Vandenbergh DJ, Persico AM, Hawkins AL, Griffin CA, Li X, Jabs EW, Uhl GR: Human dopamine transporter gene (DAT1) maps to chromosome 5p15.3 and displays a VNTR. Genomics 1992;14:1104-1106.

32 Prokhorov AV, Hudmon KS, Gritz ER: Promoting smoking cessation among cancer patients: a behavioral model. Oncology 1997; 1807-1813.

33 Heatherton TF, Kozlowski LT, Frecker RC, Fagerström KO: The Fagerström test for nicotine dependence: a revision of the Fagerström tolerance questionnaire. Br J Addict 1991;86:1119-1127.

\$34 Sieminska A, Buczkowski K, Jassem E, Niedoszytko M, Tkacz E: Influences of polymorphic variants of DRD2 and SLC6A3 genes, and their combinations on smoking in Polish population. BMC Med Genet 2009;10:92.

>35 Noble EP, St Jeor ST, Ritchie T, Syndulko K, St Jeor SC, Fitch RJ, Brunner RL, Sparkes RS: D2 dopamine receptor gene and cigarette smoking: a reward gene? Med Hypotheses 1994;42:257-260.

36 Hamajima N, Ito H, Matsuo K, Saito T, Tajima K, Ando M, Yoshida K, Takahashi T: Association between smoking habits and dopamine receptor D2 taqI A A2 allele in Japanese males: a confirmatory study. J Epidemiol 2002;12:297-304

-37 Yoshida K, Hamajima N, Kozaki Ki, Saito H, Maeno K, Sugiura T, Ookuma K, Takahashi $\mathrm{T}$ : Association between the dopamine D2 receptor A2/A2 genotype and smoking behavior in the Japanese. Cancer Epidemiol Biomarkers Prev 2001;10:403-405. 
-38 Munafò MR, Timpson NJ, David SP, Ebrahim S, Lawlor DA: Association of the DRD2 gene Taq1A polymorphism and smoking behavior: a meta-analysis and new data. Nicotine Tob Res 2009;11:64-76.

39 McGuire V, Van Den Eeden SK, Tanner CM, Kamel F, Umbach DM, Marder K, Mayeux R, Ritz B, Ross GW, Petrovitch H, Topol B, Popat RA, Costello S, Manthripragada AD, Southwick A, Myers RM, Nelson LM: Association of DRD2 and DRD3 polymorphisms with Parkinson's disease in a multi- ethnic consortium. J Neurol Sci 2011;307: 22-29.

40 Lerman C, Caporaso N, Main D, Audrain J, Boyd NR, Bowman ED, Shields PG: Depression and self-medication with nicotine: the modifying influence of the dopamine D4 receptor gene. Health Psychol 1998;17:5662.

41 Mutschler J, Abbruzzese E, von der Goltz C, Dinter C, Mobascher A, Thiele H, DiazLacava A, Dahmen N, Gallinat J, Majic T, Petrovsky N, Kornhuber J, Thuerauf N,
Gründer G, Brinkmeyer J, Wienker T, Wagner M, Winterer G, Kiefer F: Genetic variation in the neuropeptide $\mathrm{Y}$ gene promoter is associated with increased risk of tobacco smoking. Eur Addict Res 2012;18:246-252.

42 David SP, Strong DR, Munafò MR, Brown RA, Lloyd-Richardson EE, Wileyto PE, Evins EA, Shields PG, Lerman C, Niaura R: Bupropion efficacy for smoking cessation is influenced by the DRD2 Taq1A polymorphism: analysis of pooled data from two clinical trials. Nicotine Tob Res 2007;9:1251-1257. 